\title{
CARACTERIZACIÓN DEL PATRIMONIO CULTURAL EDIFICADO COMO PARTE DEL DESARROLLO SOSTENIBLE EN LA CIUDAD DE CHALCHUAPA, EL SALVADOR ${ }^{1}$
}

\author{
CHARACTERIZATION OF DEVISED CULTURAL HERITAGE AS PART OF SUSTAINABLE \\ DEVELOPMENT IN CHALCHUAPA CITY, EL SALVADOR \\ CARACTERIZAÇÃO DO PATRIMÔNIO CULTURAL EDIFICADO COMO PARTE DO \\ DESENVOLVIMENTO SUSTENTÁVEL NA CIDADE DE CHALCHUAPA, EL SALVADOR
}

Bismarck Vladimir G. Toledo Centy ${ }^{2}$

Fecha de Recibido: agosto 5 de 2016 | Fecha de Aprobación: septiembre 22 de 2016

\section{Resumen}

El crecimiento y progreso de la ciudad de Chalchuapa están poniendo en riesgo el patrimonio arquitectónico de las edificaciones del centro histórico de la ciudad. El ambiente arquitectónico con valor patrimonial ha sido sustituido por otro de carácter comercial que es contrario, con el agravante de que la norma de protección patrimonial es ineficaz. Para salvaguardar el patrimonio arquitectónico de las edificaciones del centro histórico es necesario un enfoque diferente que incluya crear normativas municipales específicas para proteger, promover y resguardar estos inmuebles. En este artículo se muestran los resultados de una investigación que caracteriza el patrimonio cultural edificado como punto de partida para el desarrollo sostenible de la ciudad de Chalchuapa. Para este fin se determinó el área, la cantidad y tipo de inmuebles con valor cultural que podrían integrarse a un plan de gestión integral de turismo sostenible; al mismo tiempo se analizó el estado de conservación de los inmuebles en el área de estudio establecida y, finalmente, se auscultó por el cumplimiento de la normativa de gestión del patrimonio edificado.

Palabras clave: Arquitectura, patrimonio cultural edificado, bienes arqueológicos, desarrollo turístico sostenible, sitios turísticos.

1 Estudio de caso.

2 Docente investigador de la Universidad Católica de El Salvador unICAES. Correo electrónico: bismarcktoledo@hotmail.com 


\section{Abstract}

The current growth and progress of Chalchuapa puts at risk the architectural heritage of historic downtown buildings. The environment with patrimonial value is replaced by other with commercial purpose that express the opposite sense, with an inefficient patrimonial protection rule as aggravating circumstance. Thus, to save the architectural heritage of historic downtown buildings, it is necessary a different approach that includes specific municipal regulation to protect, promote and save these buildings. This study aims to characterize devised cultural heritage as starting point for sustainable development in Chalchuapa. Area, quantiy and type of buildings with cultural value were determined to be integrated in an integral management plan of sustainable tourism. Likewise, conservation state of buildings was analyzed in an established area of study and finally, compliance of management regulation of devised heritage was tested.

Keywords: Architecture, built cultural heritage, archaeological property, sustainable tourism development, tourist sites.

\section{Resumo}

O crescimento e progresso da cidade de Chalchuapaestão pondo em risco o patrimônio arquitectónico das edificaciones do centro histórico da cidade, o ambiente arquitectónico com valor patrimonial é substituído por outro de caráter comercial que the é contrário, com o agravante que a norma de proteção patrimonial é ineficaz. É de modo que para salvaguardar o patrimônio arquitectónico das edificações do centro histórico é necessárioum enfoque diferente, que inclua criar regulamentosmunicipais específicas para proteger, promover e resguardar estesimóvies, como se pretende mostrar nestainvestigação, cujo objeto é caracterizar o patrimônio cultural edificado como ponto de partida para o desenvolvimentosustentável da cidade de Chalchuapa. Para este fimdeterminou-se o área, a quantidade e tipo de imóviescom valor cultural que poderiam ser integrado a um plano de gerenciamento integral de turismo sustentável; aomesmo tempo analisou-se o estado de conservação dos imóviesna área de estudoestabelecida e, finalmente, se explorou pelo cumprimento do regulamento de gerenciamento do patrimônio edificado.

Palavras-Chave: Arquitectura, património cultural edificado, bens arqueológicos, desenvolvimento turístico sustentável, lugares turísticos. 


\section{INTRODUCCIÓN}

Chalchuapa, del náhuatl Chalchihuit-a-pa: 'en agua de jade', es una ciudad del distrito homónimo del departamento de Santa Ana, ubicada en la zona occidental de El Salvador, a $13 \mathrm{~km}$ al oeste de la ciudad de Santa Ana y a $78 \mathrm{~km}$ de San Salvador. Chalchuapa atravesó los períodos arqueológicos que van desde el preclásico 1200 A.C. hasta el postclásico 100 D.C. y se convirtió en la prueba más antigua de ocupación humana en El Salvador. Posteriormente fue una ciudad colonial. La ciudad tiene gran importancia para la identidad nacional. La protección del patrimonio edificado y su contexto constituido por bienes históricos, urbanos y ambientales es una responsabilidad de todos, pues, representa la identidad y la cultura del país. No existen antecedentes históricos en los que bienes inmuebles con valor cultural sean parte de alguna estrategia, programa o plan desarrollo sostenible para la ciudad, por ello surgió esta investigación que tiene como objetivo la categorización de los inmuebles con valor cultural de Chalchuapa. Esta investigación se realizó con un enfoque cualitativo basado en el método científico, con un alcance exploratorio, ya que es un tema poco estudiado. Se agregaron a la investigación elementos de estudio explicativo que describen las características de los bienes inmuebles que podrían ser parte de una estrategia de desarrollo local.

Una parte importante de la investigación es el desarrollo de instrumentos que contabilicen, identifiquen y cataloguen estos bienes, así como proyectarlos a ser parte del desarrollo de la ciudad, no sólo desde el factor económico para evitar que por desconocimiento o falta de interés estos bienes edificados caigan en abandono, sean destruidos o dañados por sus propietarios al cambiar de uso natural de residencial a un uso comercial.

Se consideran bienes culturales los que hayan sido expresamente reconocidos como tales por el Ministerio, ya sean de naturaleza antropológica, paleontológica, arqueológica, prehistórica, histórica, etnográfica, religiosa, artística, técnica, científica, filosófica, bibliográfica y documental. Según el artículo 7 de la Ley Especial de Protección al Patrimonio Cultural de El Salvador, "los municipios, para los fines de conservación de los bienes culturales de su circunscripción, se atendrán a las normas y técnicas que dicte el Ministerio".
La ciudad de Chalchuapa posee muchos bienes de valor cultural edificado, entre los cuales se pueden mencionar: estructuras precolombinas, iglesias coloniales y arquitectura con valor histórico. Estas edificaciones están dentro de las siguientes categorías: monumentos, conjuntos históricos, centros históricos, sitios históricos y zonas arqueológicas (artículo 10 del Reglamento de la Ley Especial de Protección al Patrimonio Cultural de El Salvador).

Otra parte importante de la investigación es conocer históricamente y conceptualmente Chalchuapa para determinar el espacio físico y las condicionales actuales. Aspectos importantes que proporcionan los inventarios para el desarrollo y aplicación de las ordenanzas en pro del patrimonio cultural.

El inventario puede generar desarrollo desde la cultura y la identidad cultural y facilita la obtención de datos que permiten proponer planes de conservación, ordenamiento del casco urbano, según lineamientos de la Ley Especial de Protección al Patrimonio Cultural de El Salvador y su reglamento. El inventario de caracterización puede proporcionar la base necesaria para proponer declaratorias legales a zonas, conjuntos históricos o inmuebles aislados con valor cultural.

Los siguientes son criterios para inventariar:

- Valor de antigüedad: Los inmuebles tienen más de 50 años de construcción.

- Valor histórico: Deben haber sido testigos de hechos históricos relevantes. Haber sido lugares donde nacieron, vivieron o se desarrollaron personajes célebres de la historia.

- Puede constituir un sitio histórico donde existió un inmueble antiguo ocupado hoy por uno nuevo, o el lugar donde se dio un hecho histórico o que fuese un edificio público importante.

- Valor tecnológico: Sistema o técnica constructiva que marcó una diferencia en la tecnología de la época en la que fue construido.

- Valor urbano: Integrado con valor individual o de conjunto en una zona con características comunes y que además presenten un valor arquitectónico o artístico que la haga sobresalir del conjunto o no.

- No integrado con valor: es aquella edificación que no forma parte de una zona característica 
común (fachadas), pero representa un valor arquitectónico o artístico.

- Elemento de significación máxima, hito urbano o nodo, que es considerado por la población como referencia.

- Valor arquitectónico: Debe manifestar tendencia a un estilo arquitectónico determinado. Cuando el inmueble posee calidad arquitectónica y artística constituyendo un todo armónico. Su esencia no está alterada. Representativa de una época, siendo ejemplo típico de una corriente arquitectónica o constructiva.

\section{METODOLOGÍA}

\section{Tipo de estudio}

La investigación se realizó con un enfoque cualitativo. Se hizo recolección y análisis de datos para describir de forma detallada situaciones, eventos, personas, conductas observadas y manifestaciones del fenómeno planteado. La investigación estuvo enfocada como una serie de procesos ordenados, críticos y empíricos que se aplican al estudio de un fenómeno; en este caso, a la situación actual de los inmuebles con valor cultural de la ciudad de Chalchuapa.

Basada en el método científico, la investigación tuvo un alcance exploratorio porque realizó estudios pioneros en el tema; a su vez, agregó características de estudio explicativo, dado que midió y recolectó datos sobre la situación actual en el tema.

\section{Población y muestra}

Personas entre funcionarios públicos, inversionistas y profesionales que tenían algún interés e injerencia en el patrimonio cultural edificado, así como en el desarrollo de ciudad de la Chalchuapa.

Muestra: de la población se seleccionaron funcionarios públicos de las instituciones pertinentes, inversionistas (dos empresarios interesados en establecer negocios en el área de estudio) y 30 residentes del área de estudio. De esta manera, quedaron representados todos los grupos que tienen algún interés e injerencia en el patrimonio cultural edificado, así como en el desarrollo turístico de Chalchuapa. Se realizó un muestreo aleatorio simple.

\section{Técnicas e instrumentos de investigación}

Con el objetivo de analizar, catalogar, determinar el estilo al que pertenece cada inmueble y establecer su estado de conservación, en el área de estudio se crearon fichas de análisis, las cuales se dividieron en dos tipos:

1. Fichas propias de categorización arquitectónica de bienes inmuebles:

- Ficha 1. Delimitación del área de estudio: se utilizó esta ficha para mostrar el criterio de delimitación utilizado: pertenecer al centro histórico de la ciudad y que existiera homogeneidad en el perfil urbano. Se obtuvo como resultado un radio de $\mathbf{2 0 0}$ metros a partir de la manzana cero donde se ubica la iglesia principal.

- Ficha 2. Determinaciones de perfiles urbanos: son manzanas que poseen el criterio en las que la mayoría de inmuebles presenta características pertenecientes a tipologías arquitectónicas, lo que da una unidad visual a toda la manzana.

- Ficha 3. Determinaciones de inmuebles relevantes: son inmuebles que poseen algún tipo de valor patrimonial: valor de antigüedad, histórico, tecnológico, arquitectónico o urbano.

- Ficha 4. Identificación de centros históricos de Chalchuapa cumpliendo con los criterios de: 1) ubicación, 2) perfil urbano (tipo de traza, espacios de interés, hitos urbanos, homogeneidad de tejido urbano), 3) inmuebles relevantes, 4) estado de conservación, 5) protección existente, 6) uso de suelo predominante, 7) situación actual y 8) potencial de desarrollo.

2. Fichas de categorización arquitectónica basadas en el catálogo de bienes inmuebles de la Secretaría de la Cultura:

- Ficha 5. Análisis de bienes con valor patrimonial: esta ficha es para inmuebles relevantes que presentan un valor cultural para la ciudad y cumpliendo con los criterios de determinar lo siguiente: 1) identificación de inmueble (mapa de manzana, identificación fotográfica, departamento, municipio, dirección), régimen de propiedad, protección legal y valor urbano; 2) exterior del inmueble (tipo de predio, tipo de fachada, línea de construcción, remate de fachada, número de alturas, tipo de ventanas, tipo de balcones, tipo de puerta, tipo de remate de puerta y tipo de techo) y 3) interior del inmueble (planta arquitectónica, entrepiso, material de construcción material 
de piso, escaleras y material de cubierta).

- Ficha 6. Instrumento: cuestionarios de tipo de caracterización con 10 preguntas cerradas para los entrevistados. Los criterios de los cuales se pretendió obtener resultados fueron:

3. Tipo de régimen de propiedad: con el objetivo de relacionar esta variable con el estado de conservación de los mismos.

4. Conocimiento del valor cultural de los inmuebles debido a la pertenencia dentro del radio del centro histórico que cuenta con protección y regulación de la Secretaría de Cultura. El objetivo fue medir el nivel de conocimiento de los propietarios o usuarios y del tipo de valor cultural que poseen los inmuebles.

5. Regulaciones de las modificaciones que sufren los inmuebles, si estas modificaciones fueron reguladas por los entes encargados, ya sea la Secretaría de la Cultura o el Departamento de Ingeniería de la Alcaldía de Chalchuapa.

6. La percepción de la eficacia de la Secretaría de la Cultura: escultura en la regulación de los bienes inmuebles con valor cultural.

\section{Procedimiento}

Se requirió de la recolección de información, consultando primeramente fuentes bibliográficas, documentos privados y oficiales. Cabe destacar que las fuentes oficiales locales o nacionales acerca del tema fueron mínimas porque no existen estrategias, programas, proyectos o proyectos a nivel local en la alcaldía de Chalchuapa, departamento de Santa Ana. A nivel nacional no se pudo tener acceso para determinar la existencia de algún plan que incluya el tema del patrimonio como un agente de desarrollo, aunque en la parte de patrimonio cultural se tuvo acceso a un Manual de preservación de inmuebles y a un Manual de catálogo de bienes urbanos con valor cultural. De la Secretaría de Cultura, que sirvió de base para la ficha 5 , se realizaron fichas de cada inmueble relevante; sólo se agregó por factor espacio la ficha 1 de la Iglesia Santiago Apóstol.

Se diseñaron, además, fichas propias para sintetizar la información recolectada por medio de la investigación bibliográfica y la observación in situ de las características arquitectónicas de los inmuebles con valor arquitectónico y de los centros urbanos con valor de perfil urbano. Asimismo, se realizaron cuestionarios que se aplicaron a los residentes que hicieron parte de la muestra; dado que el número de residentes es mayor, un cuestionario cerrado es el instrumento más adecuado para reflejar sus opiniones.

\section{RESULTADOS}

Al culminar con el objetivo general de la investigación se hizo el siguiente análisis:

Ficha 1. Delimitación del área de estudio: se delimitó esa área de estudio dentro del centro histórico de la ciudad, ya que cuenta con inmuebles con algún tipo de valor patrimonial, así como ejes que mantienen el perfil urbano

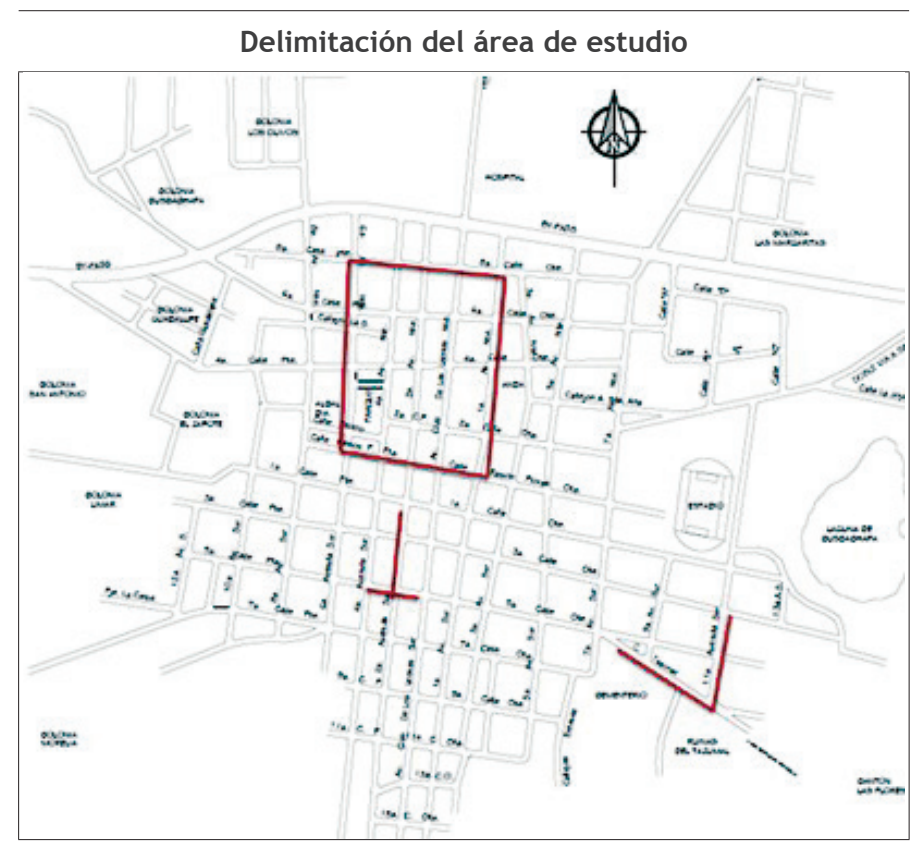

Fuente: elaboración propia. 
Ficha 2. Determinaciones de perfiles urbanos. Son inmuebles que tienen ciertas características pertenecientes a tipologías arquitectónicas lo que da una unidad visual a toda la manzana

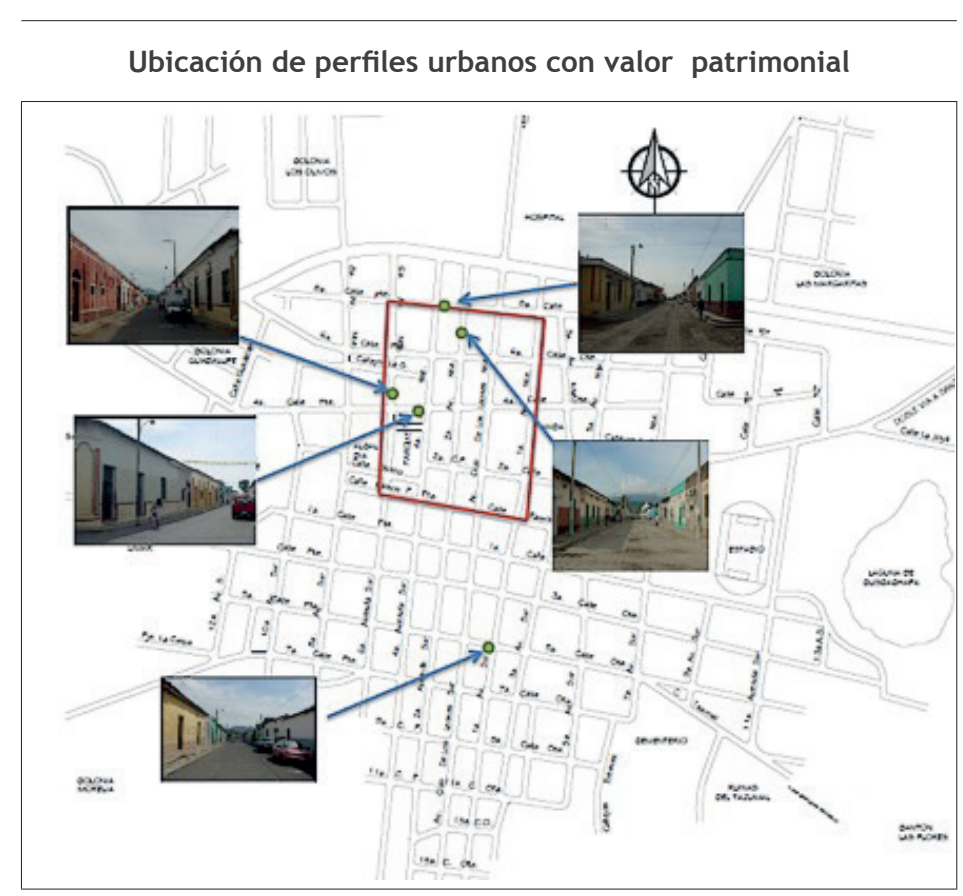

Fuente: elaboración propia.

Ficha 3. Determinaciones de inmuebles relevantes. Son inmuebles que tienen alguno de los tipos de valor patrimonial: valor de antigüedad, histórico, tecnológico, arquitectónico o urbano

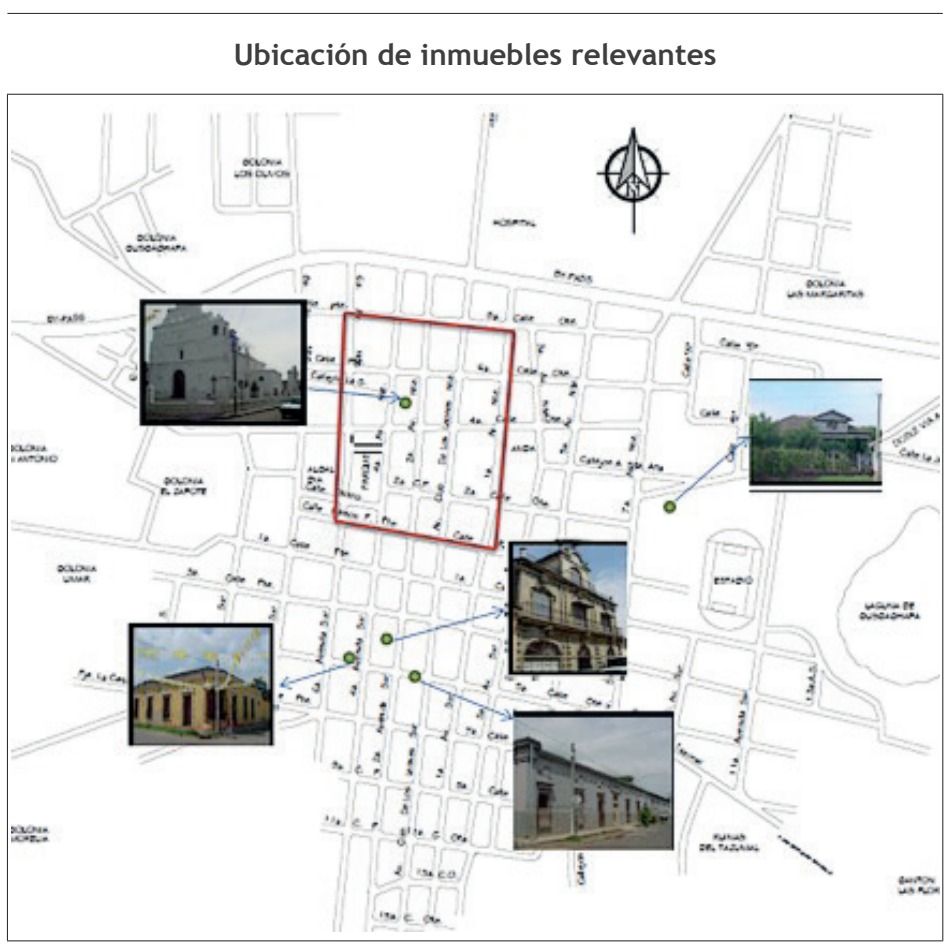

Fuente: elaboración propia. 
- La propia arquitectura del lugar.

- Sitio arqueológico el Trazumar (calle al tazumal y $11^{\mathrm{a}}$ av. sur).

- Sitio arqueológico casa blanca (by pass y costado pte. col. las margaritas).

- Balneario el trapiche. (Calle al cantón san Juan chiquito, $1 \mathrm{~km}$ al norte de la ciudad).

- Balneario Galeano (a $5 \mathrm{~km}$ al norte de la ciudad).

- Laguna Cuscachapa (11 a av. nte. contiguo al instituto nacional Jorge Elías Azucena Ortega).

- La producción de artesanías: tallados en piedra jade y caliza, alfarería y tallado de cuero.

- Celebración de sus fiestas patronales del 10 al 16 de agosto.

\section{OBSERVACIONES}

Esta ciudad presenta un centro histórico con alto potencial cultural y en buen estado de conservación, por lo que urge el establecimiento de una ordenanza de protección del mismo.

Ficha 5. Identificación de inmuebles $1^{3}$

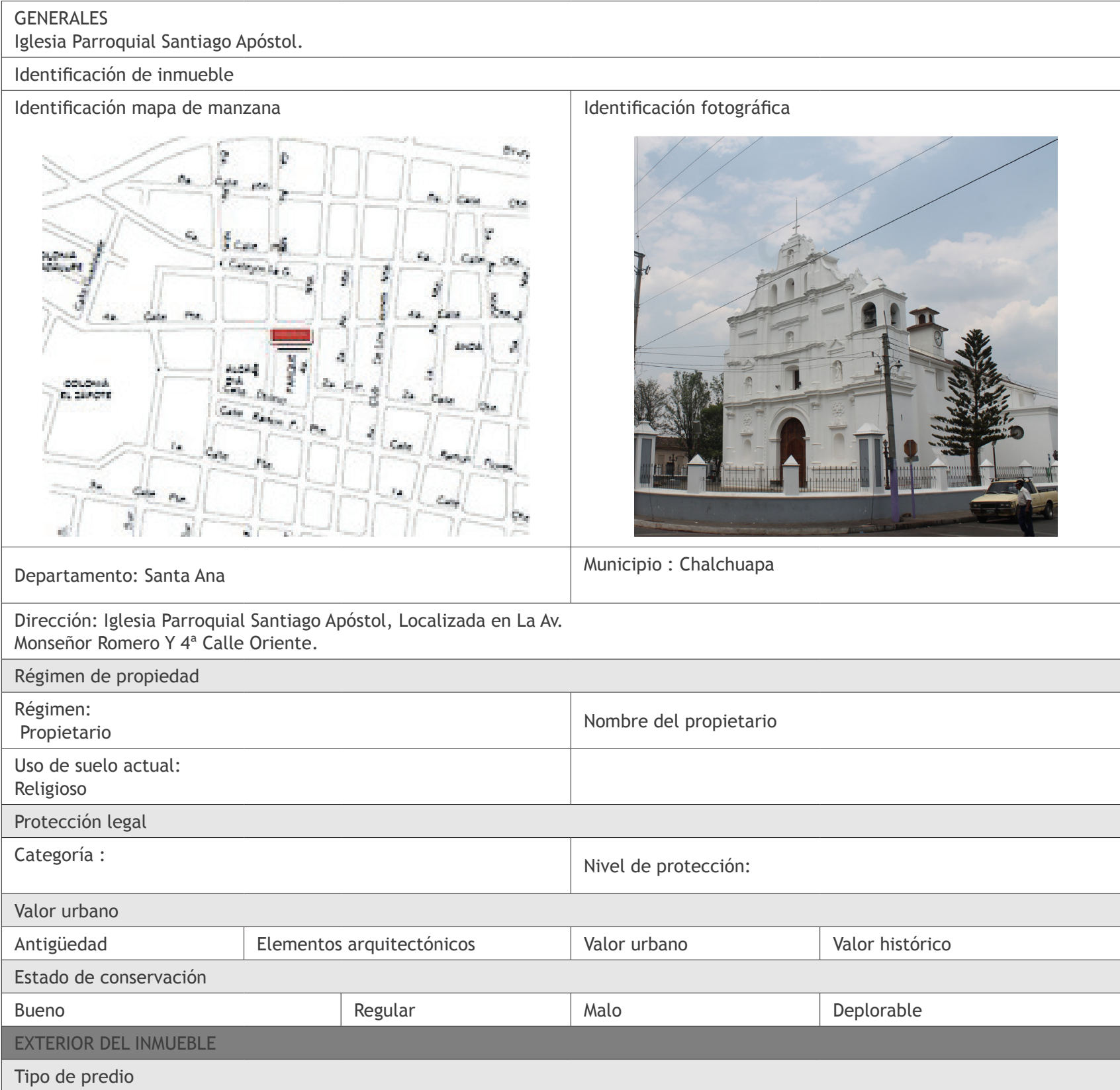

3 Basado en el inventario de Bienes Culturales Inmuebles $(\mathrm{BCl})$, metodología utilizada por Secretaria de Cultura. 


\begin{tabular}{|c|c|c|c|}
\hline Medianero & Esquina & Manzana completa & Otro \\
\hline \multicolumn{4}{|c|}{ Línea de construcción } \\
\hline Original & Modificada & Regular & Irregular \\
\hline \multicolumn{4}{|l|}{ Tipo de fachada } \\
\hline Recta & Esquina curva & Esquina ochave & Atrio \\
\hline Pórtico & Otros & & \\
\hline \multicolumn{4}{|c|}{ Tipo de remate de fachada } \\
\hline Recta & Curva & Retranqueada & Ochave \\
\hline Discontinua & Otros & & \\
\hline \multicolumn{4}{|l|}{ Número de alturas } \\
\hline Número de niveles & $0-3$ metros & 3-6 metros & 6-9 metros \\
\hline \multicolumn{4}{|l|}{ Tipo de ventanas } \\
\hline Vano recto & Vano con arco & Con moldura & Con tímpano \\
\hline \multicolumn{4}{|l|}{ otros } \\
\hline \multicolumn{4}{|l|}{ Tipo de balcones } \\
\hline Rectilíneo & Cóncavo & Dibujo & Antepecho \\
\hline \multicolumn{4}{|l|}{ Tipo de puertas } \\
\hline Vano recto & Vano curvo & Con moldura & Con tímpano \\
\hline \multicolumn{4}{|l|}{ Otros } \\
\hline \multicolumn{4}{|l|}{ Tipo de remate } \\
\hline Cornisa & Alero & Antepecho & Balaustrada \\
\hline \multicolumn{4}{|l|}{ Tipo de techo } \\
\hline 1 agua & 2 aguas & Bóveda & Losa \\
\hline \multicolumn{4}{|c|}{ INTERIOR DEL INMUEBLE } \\
\hline \multicolumn{4}{|c|}{ Planta arquitectónica } \\
\hline Patio central & Patio posterior & Forma de U & Forma de $\mathrm{L}$ \\
\hline Cruz latina & Otros & & \\
\hline \multicolumn{4}{|l|}{ Entrepiso } \\
\hline Concreto & Madera & otros & \\
\hline \multicolumn{4}{|c|}{ material de construcción } \\
\hline Adobe & Bahareque & Lamina troquelada & Concreto \\
\hline \multicolumn{4}{|l|}{ Material de piso } \\
\hline Cemento & Madera & Otros & \\
\hline \multicolumn{4}{|l|}{ Escaleras } \\
\hline Recta & Curva & En forma de u & En forma de $L$ \\
\hline \multicolumn{4}{|l|}{ Otros } \\
\hline \multicolumn{4}{|l|}{ Material de cubierta } \\
\hline Teja & Lámina de asbesto & Lámina galvanizada & otros \\
\hline
\end{tabular}

Fuente. elaboración propia. 


\section{ESTILOS ARQUITECTÓNICOS IDENTIFICADOS EN EL CENTRO HISTÓRICO DE CHALCHUAPA. TIPOLOGÍAS ARQUITECTÓNICAS}

En general, la arquitectura salvadoreña fue influenciada por los estilos arquitectónicos traídos de Europa y de los Estados Unidos. Durante todo el desarrollo de la arquitectura salvadoreña, desde la conquista a la actualidad, se ha visto diversificada debido a la transculturación en la que ha estado inmerso el país, por la dependencia económica, cultural.

La influencia de los estilos arquitectónicos en El Salvador está condicionada por los siguientes aspectos:

- Marca un predominio de influencias estilísticas en las edificaciones del sector social predominante debido a que ellos, por su nivel cultural y social, traían del extranjero nuevas ideas. Asimismo, tenían las posibilidades para contratar constructores.

- La arquitectura que se dio en el país fue adaptada al medio en que se desarrollaba, puesto que el clima salvadoreño varía notablemente con el de Europa y Estados Unidos. A la vez empleaban materiales constructivos propios de la zona, facilitando su uso.

- El desfase de época entre el aparecimiento de los estilos arquitectónicos en el mundo y la llegada de estos al país, se refleja a partir de la segunda mitad del siglo XX con una diferencia aproximada de 50 años, lo cual disminuye adelantos en la comunicación para la evolución de la arquitectura.

Los estilos arquitectónicos son los presentes en el área de estudio determinada, así como las imágenes son de viviendas e inmuebles presentes en el área de estudio.

\section{Estilo colonial}

Figura 1. Estilo colonial

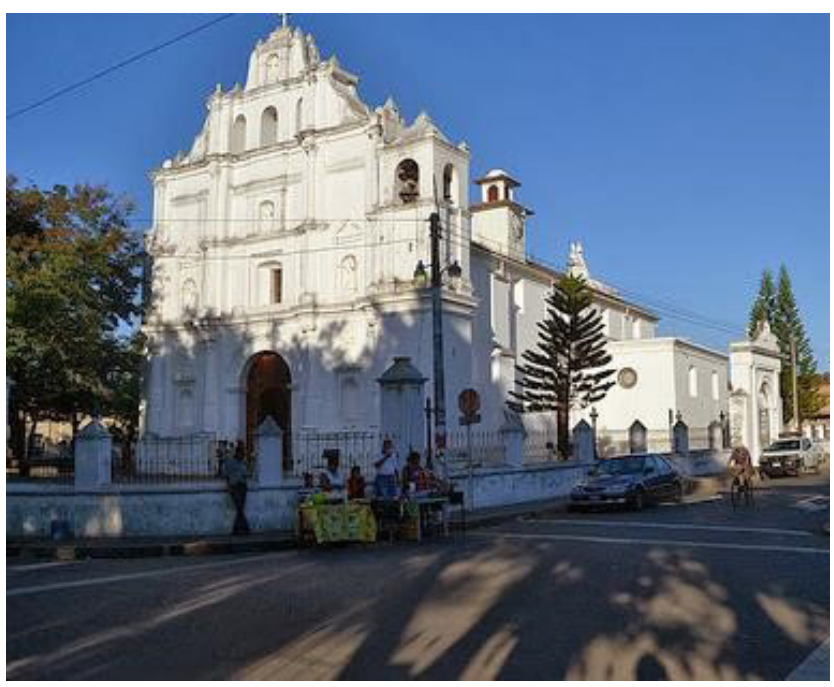

Fuente: fotografía tomada por el autor.

La arquitectura de este periodo fue influenciada en las diferentes edificaciones de carácter habitacional, religioso y político. Tiene un estilo propio nacido de la mezcla del clima y los materiales del nuevo mundo y la influencia de los conquistadores.

En esta época, la colonial, los españoles introdujeron la funcionalidad de espacios y formas de utilización de los materiales existentes. En la arquitectura colonial se puede observar una arquitectura sin precedentes, por ejemplo, en las iglesias construidas en la época de la colonia, con sus grandes contrafuertes y sus columnas salomónicas. En esta época se introdujeron materiales como la teja de barro, el ladrillo de barro cocido, madera labrada y tratada para acabados de cielo falso, pilares, vigas, puertas y ventanas. 


\section{Estilo neoclasicismo}

Se distingue por una búsqueda de los principios clásicos Grecorromanos. Surge en Europa y EE.Uu. en 1750, en El Salvador en 1890. Busca recuperar el lenguaje formal de la arquitectura grecorromana y el renacimiento.

Figura 2. Estilo neoclacismo

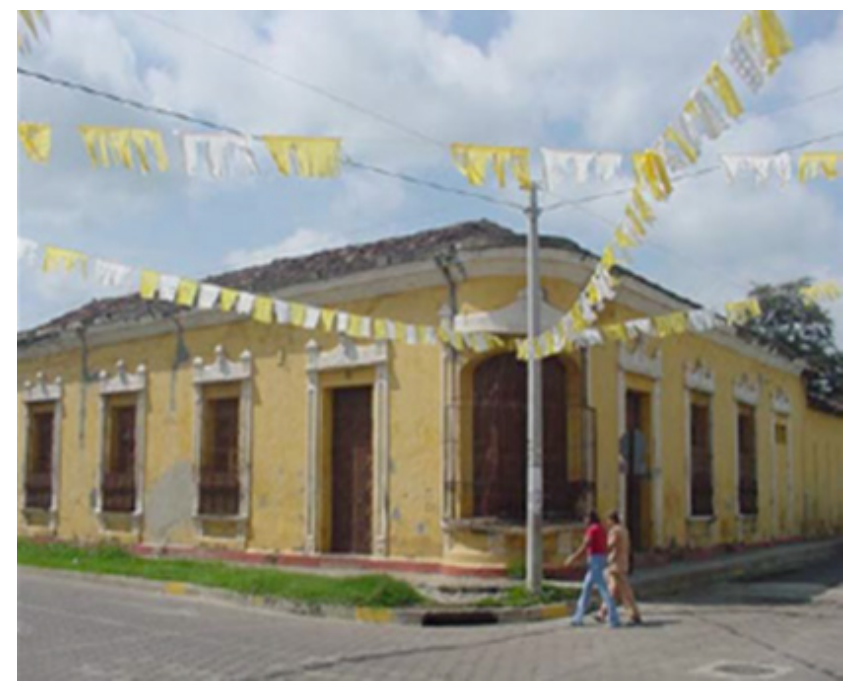

Fuente: fotografía tomada por el autor.

\section{Características:}

- Predominio de la línea recta, las formas geométricas en el volumen (cubo, cilindro, pirámide, esfera). Uso de columnas monumentales.

- Sencillez en la ornamentación. Aspectos rígidos y monumentales. Uso de frontones en puertas y ventanas.

- Uso de pilastras adosadas con capitel clásico y basamento en las fachadas.

- Uso de espacios con alturas cercanas a los cinco metros por nivel.

- Uso de herrería labrada en forja en ventanas y balcones.

- En las esquinas se manifiesta una pilastra adosada en cada parámetro separadas por el vértice remetido.

\section{Eclecticismo local}

Figura 3. Eclecticismo local

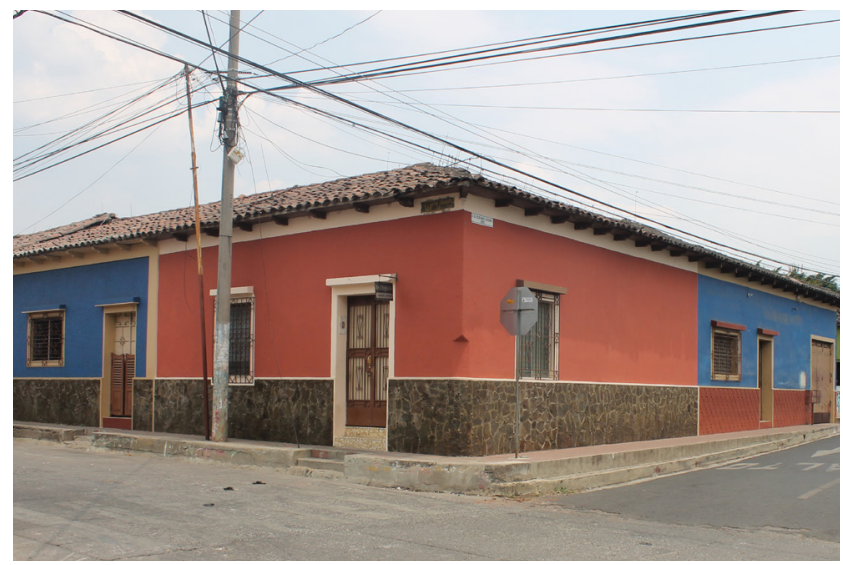

Fuente: fotografía tomada por el autor.

Es resultado de combinaciones de estilos mundiales y la arquitectura salvadoreña. Ésta es propia y auténtica del país y se caracteriza por la sencillez de líneas en las fachadas combinadas con detalles decorativos de los estilos arquitectónicos extranjeros, resultando así un eclecticismo local.

\section{Eclecticismo}

Figura 4. Eclecticismo

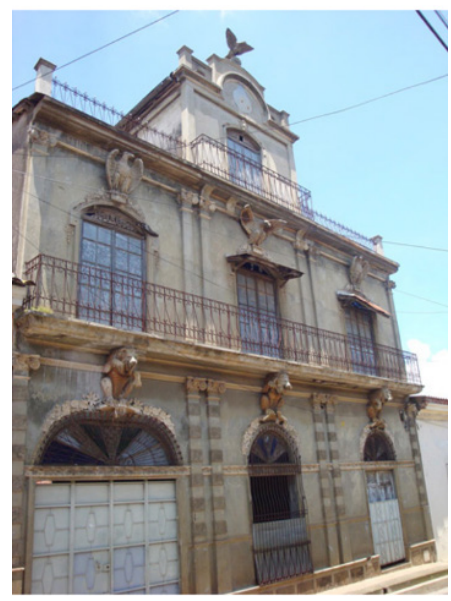

Fuente: fotografía tomada por el autor. 
Se da un enriquecimiento ornamental, ejecutado sobre la estructura compositiva neo-clásica, respetando y produciendo variaciones ajenas a los estilos grecorromanos.

Introducción de ornamentación zoomorfa en forma de cartelas, ménsulas, medallones, florones, guirnaldas y escudos realizados de cantería o estuco. Herrería ligera, labrada con gran variedad formal en ventanas y balcones.

\section{Art déco}

Figura 5. Art déco

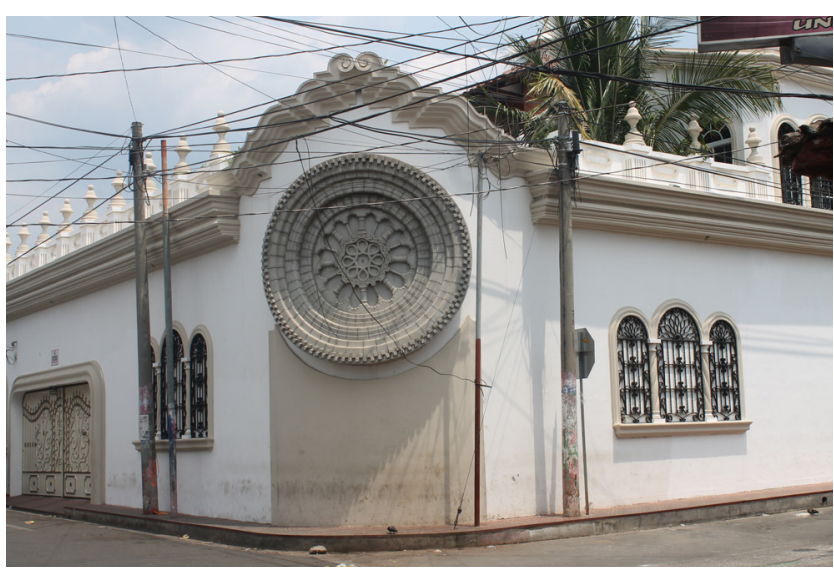

Fuente: fotografía tomada por el autor.

Se caracteriza por su afán decorativo por encima de la funcionalidad. Se dio apremiadamente de 1930 a 1950 . Se basa principalmente por sus figuras geométricas, conjuntos horizontales y verticales de líneas rectas, o perpendiculares combinadas con medias circunferencias y circunferencias enteras. Además por lo siguiente:

- Uso de hexágonos y octágonos.
- Utilización de remates terminados escalonadamente.

- Uso de líneas definidas, en un juego entre horizontales y verticales.

- Espacios largos de grandes alturas. Riqueza ornamental de las superficies en el exterior de los edificios.

- Uso de frontones en graderías.

- Herrería en puertas y ventanas, con diseños geométricos acristalados.

\section{Arquitectura popular}

Figura 6. Arquitectura popular

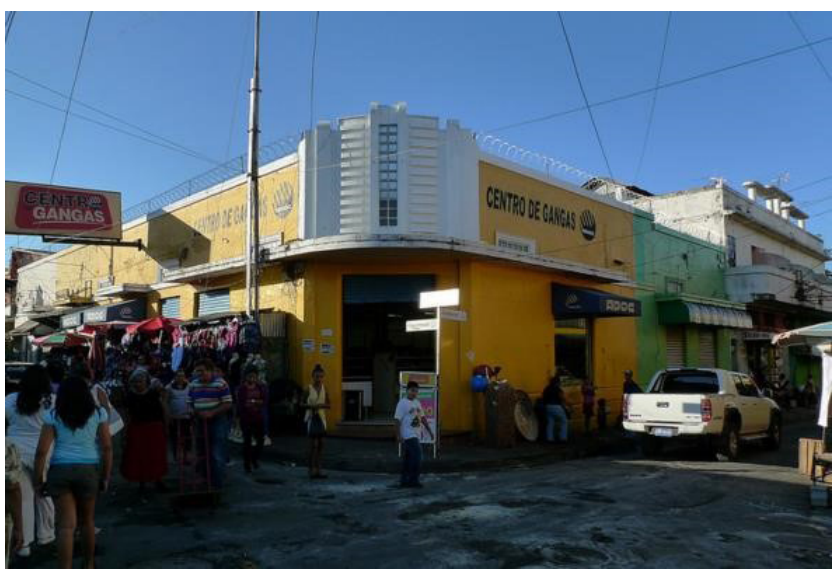

Fuente: fotografía tomada por el autor.

Este tipo de arquitectura surge en el Salvador porque la mayoría de viviendas no son diseñadas por profesionales, los propietarios proponen sus espacios, formas y los materiales más baratos y aparentemente estéticos. Lo negativo de estas construcciones no son sus fachadas o elementos decorativos, sino la inseguridad de sus cimientos, sus estructuras débiles ante un sismo o terremoto, ya que en sus fundaciones y procesos constructivos no se tomó en cuentan ningún lineamiento de ley de urbanismo de construcción. 
Ficha 6. Cuestionario de preguntas cerradas con la finalidad de analizar la percepción de los habitantes de la zona seleccionada

CUESTIONARIO DE VALORACIÓN DE BIENES INMUEBLES

1. Ubicación del inmueble

2. ¿Cuál es el tipo de régimen de propiedad del inmueble?

\begin{tabular}{l|l|l} 
a. Propietario & b. Alquiler & Concesión \\
\hline
\end{tabular}

3. ¿Sabía usted que su vivienda está dentro del radio de Centro Histórico de la Ciudad de Chalchuapa?

\begin{tabular}{|c|l|l|l|}
\hline a. Sí & b. No & \\
\hline \multicolumn{3}{|l|}{} \\
\hline 4. ¿Sabía usted que su vivienda tiene algún valor de Bien Cultural patrimonial? & \\
\hline a. Sí & b. No & & \\
\hline
\end{tabular}

5. ¿Qué tipo de valor cultural cree que tiene su inmueble?

\begin{tabular}{|l|l|l|l|}
\hline a. Antigüedad & b. $\begin{array}{l}\text { Elementos } \\
\text { arquitectónicos } \\
\text { representativos }\end{array}$ & c. $\begin{array}{l}\text { Representar un estilo } \\
\text { arquitectónico }\end{array}$ & d. Ser un hito arquitectónico \\
\hline
\end{tabular}

6. ¿Ha realizado algún tipo de construcción, remodelación o intervención al inmueble en los últimos 5 años?
a. Sí
b. No

7. ¿Producto de esa intervención SECULTURA realizó algún tipo de regulación?

\begin{tabular}{|c|c|c|c|}
\hline a. Sí & b. No & & \\
\hline \multicolumn{2}{|c|}{} \\
\hline
\end{tabular}

8. ¿Cómo calificaría la regulación de SECULTURA?

\begin{tabular}{|c|c|c|c|c|c|}
\hline & $\begin{array}{l}\text { Útil y } \\
\text { técnica }\end{array}$ & & $\begin{array}{l}\text { Demasiado } \\
\text { tiempo de } \\
\text { resolución }\end{array}$ & c. Innecesaria & d. Ignore a SECULTURA \\
\hline
\end{tabular}

9. ¿Producto de esa intervención la Unidad de Ingeniería de la Alcaldía realizó algún tipo de regulación?

\begin{tabular}{|c|c|c|c|}
\hline a. Sí & b. No & & \\
\hline \multicolumn{4}{|c|}{ 10. ¿Cómo calificaría la regulación de La Unidad de Ingeniería de la Alcaldía? } \\
\hline $\begin{array}{l}\text { e. Útil y } \\
\text { técnica }\end{array}$ & $\begin{array}{l}\text { f. Demasiado } \\
\text { tiempo de } \\
\text { resolución }\end{array}$ & g. Innecesaria & h. Ignore a la alcaldía \\
\hline
\end{tabular}

Fuente: elaboración propia. 


\section{RESULTADOS}

Pregunta 2. ¿Cuál es el tipo de régimen de propiedad del inmueble?

\begin{tabular}{|r|r|r|r|r|}
\hline a. Propietario & b. Alquiler & c. Concesión & d. Otro & Total \\
\hline 16 & 12 & 0 & 4 & 30 \\
\hline
\end{tabular}

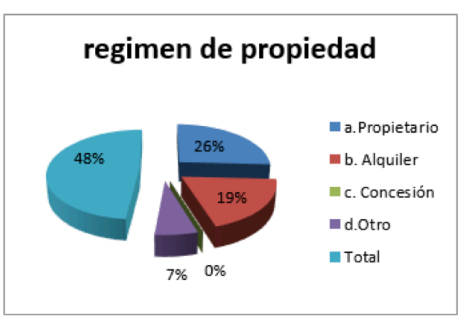

En la imagen se observa que solo el $48 \%$ son propietarios de los inmuebles, esta es una razón del deterioro de los bienes patrimoniales ya que los inquilinos invierten poco en mantenimiento de los mismos.

Fuente: elaboración propia.

Pregunta 3. ¿Sabía usted que su vivienda está dentro del radio de Centro Histórico de la Ciudad de Chalchuapa?
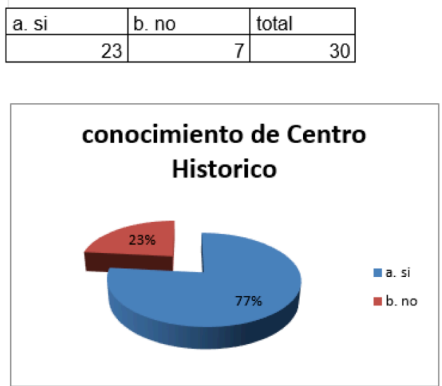

En el gráfico podemos evidenciar que el $77 \%$ tiene conocimiento que el inmueble se encuentra dentro del radio de centro historico.
Fuente: elaboración propia.
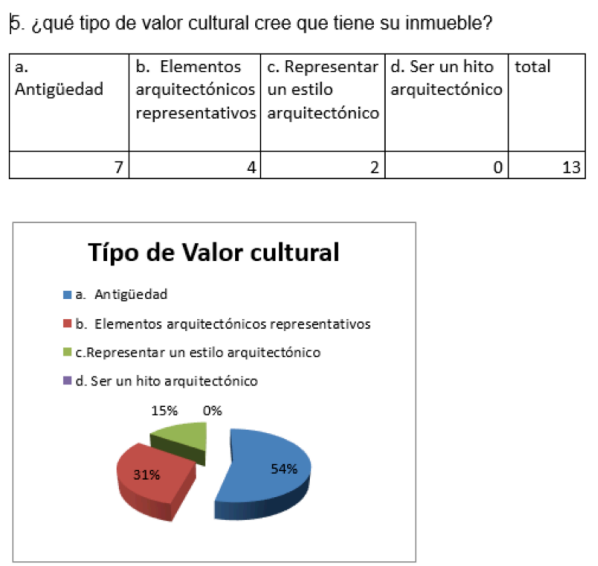

En la gráfica se refleja la percepcion del tipo de valor cultural: $54 \%$ de los inmuebles tienen un valor cultural por antigüedad, el $32 \%$ por elementos arquitectónicos relevantes aunque son elementos aislados y sólo el 13\% representana un estilo arquitectónico.

Fuente: elaboración propia.
6. ¿ha realizado algún tipo de construcción intervención o remodelación al inmueble en los últimos 5 años?
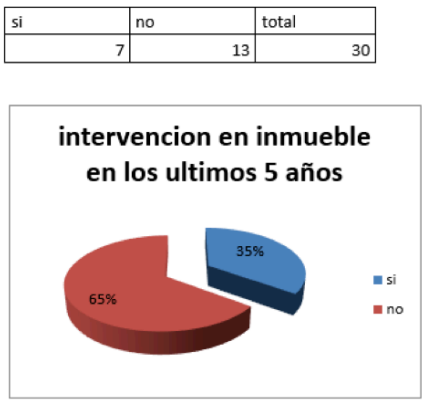

La gráfica muetra que el $35 \%$ de los inmuebles han sufrido un tipo de intervencion, sería este porcentaje el que se encuentra en riesgo.

Fuente: elaboración propia.

7. ¿producto de esa intervención SECULTURA realizo algún tipo de regulación?

\begin{tabular}{|l|l|l|l|}
\hline si & no & total \\
\hline & 5 & 2 & \\
\hline
\end{tabular}

\section{Efectividad de SECULTURA}

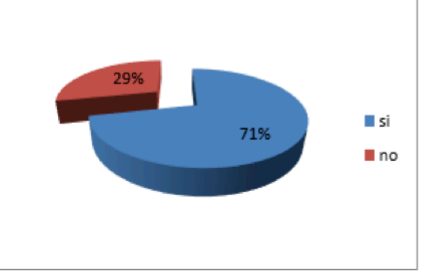

La gráfica nos muestra el grado de efectividad, $71 \%$ de parte de la Secretaría de Cultura en regular los inmuebles que son intervenidos.

Fuente: elaboración propia.

8. ¿cómo calificaría la regulación de SECULTURA?

\begin{tabular}{|r|l|r|r|r|}
\hline $\begin{array}{c}\text { a. Útily } \\
\text { técnica }\end{array}$ & $\begin{array}{l}\text { b. Demasiado } \\
\text { tiempo de } \\
\text { resolución }\end{array}$ & c. Innecesaria & $\begin{array}{c}\text { d. Ignore a } \\
\text { SECULTURA }\end{array}$ & Total \\
\hline 2 & 1 & 1 & & 3 \\
\hline
\end{tabular}

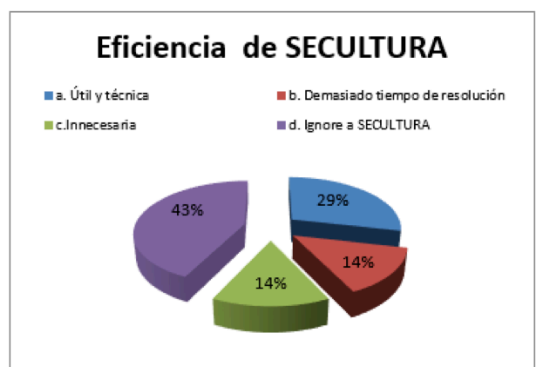

La gráfica muestra la percepción de la eficiencia de la Secretaria de Cultura en regular los inmuebles que son intervenidos.

El $29 \%$ considera que es útil y técnica, el $14 \%$ considera que es un proceso muy lento, otro $14 \%$ que es innecesaria, y el $43 \%$ ignoró las recomendaciones.

Fuente: elaboración propia. 
A continuación, se presentan fotografías de las diversas arquitecturas urbanísticas del centro histórico de Chalchuapa.

\section{ESPACIOS ABIERTOS DE INTERÉS}

Figura 7. Parque José Matías Delgado
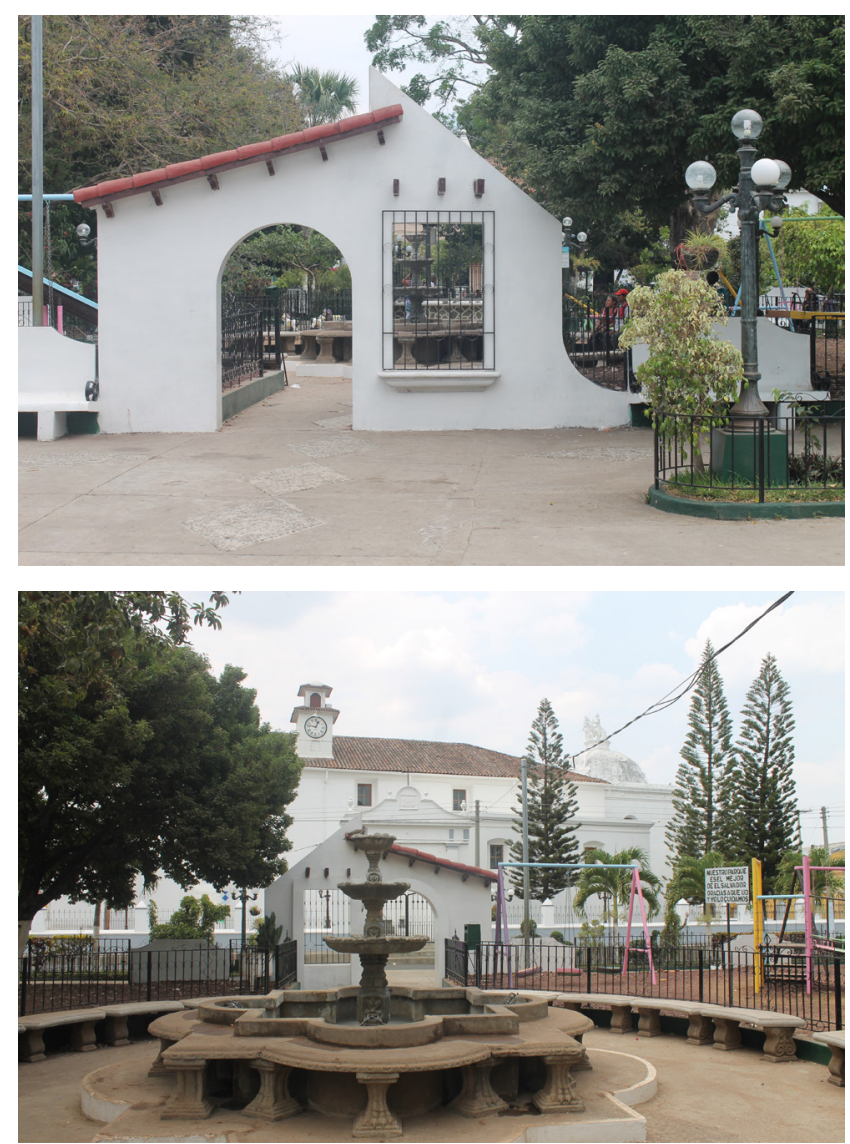

Fuente: fotografía tomada por el autor.

Figira 8. Parque Santiago Apóstol

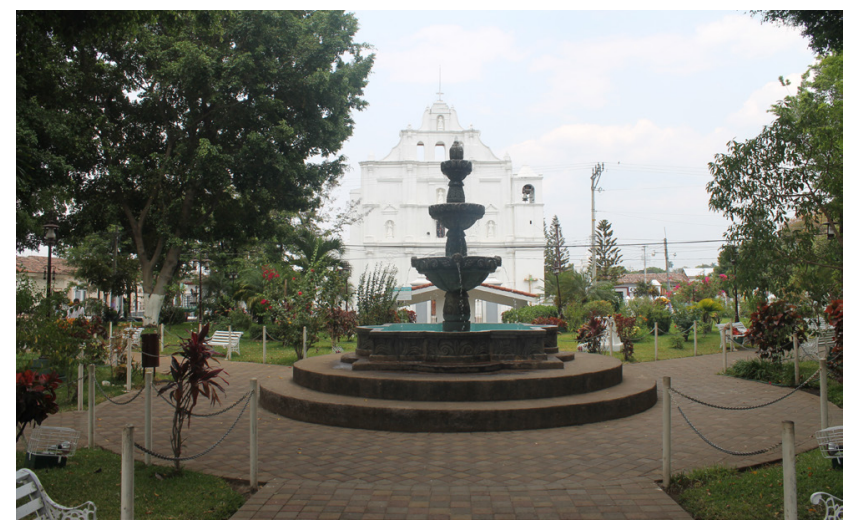

Fuente: fotografía tomada por el autor.
Figura 9. Monumento a la Madre

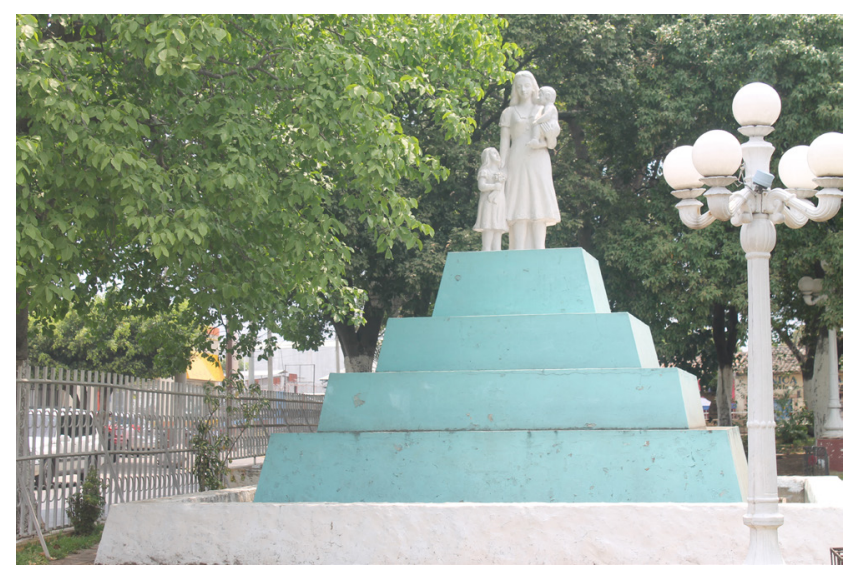

Fuente: fotografía tomada por el autor.

\section{HITOS URBANOS}

Figura 10. Sitio Arqueológico El Tazumal

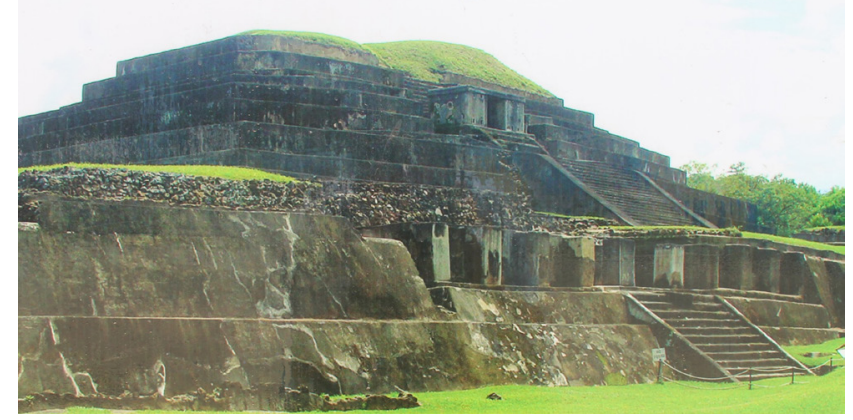

Fuente: fotografía tomada por el autor.

Figira 11. Sitio Arqueológico Casa Blanca

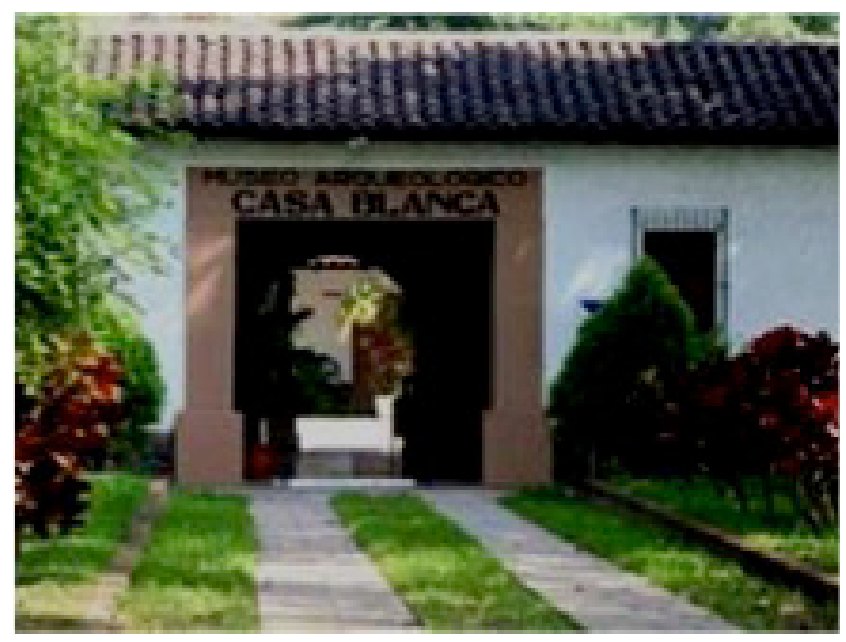

Fuente: fotografía tomada por el autor. 
Figira 12. Parroquia El Calvario

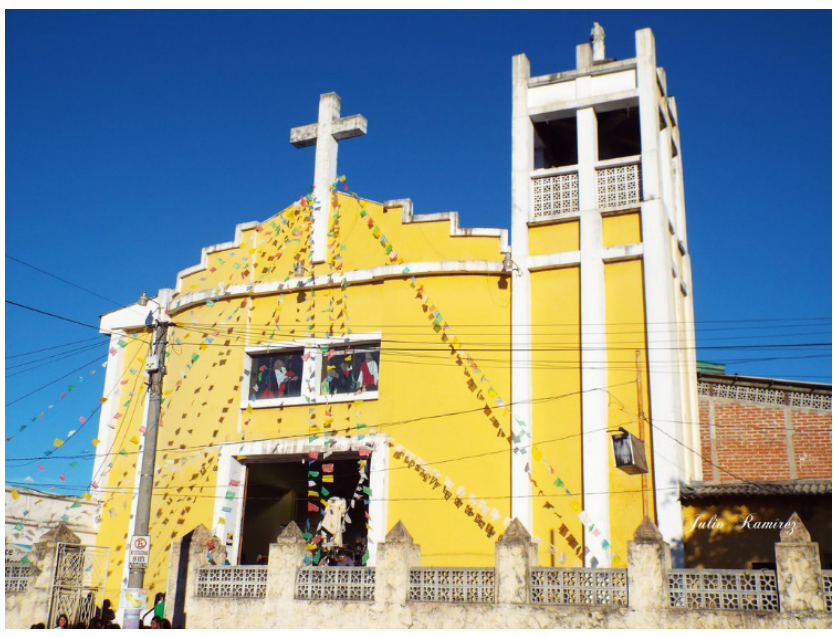

Fuente: fotografía tomada por el autor.

\section{INMUEBLES RELEVANTES}

Figura 13. Vivienda particular

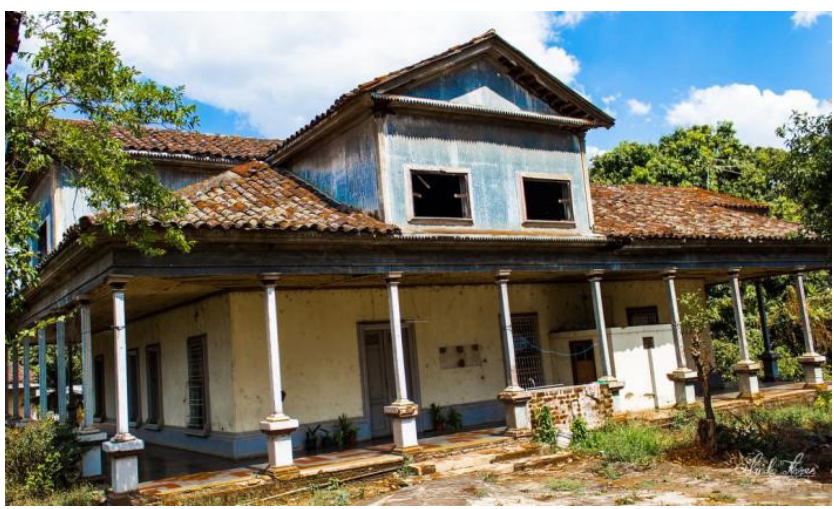

ळ

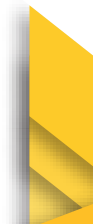

Figura 15. Vivienda particular

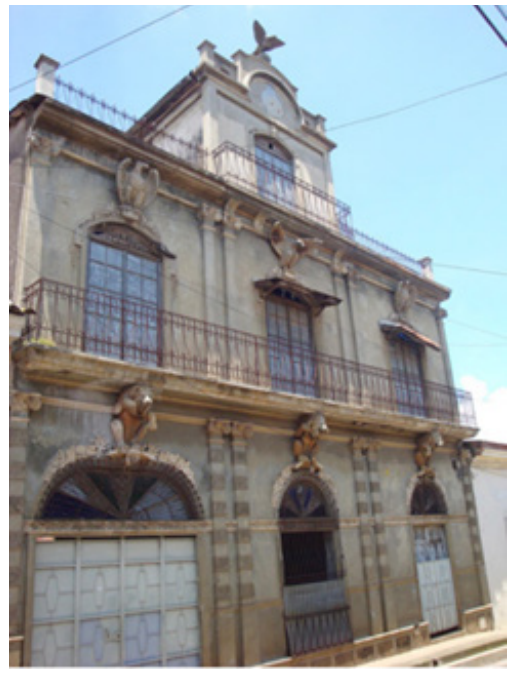

Fuente: fotografía tomada por el autor.

\section{DISCUSIÓN Y/O CONCLUSIÓN}

El patrimonio cultural salvadoreño, por lo que respecta a sus centros históricos e inmuebles relevantes con valor cultural, se vio gravemente dañado por los sismos acaecidos en el 2001, según datos proporcionados por Secultura. En el caso específico de la ciudad de Chalchuapa el edificio más representativo, a saber, la parroquia de Santiago Apóstol, percibió daños catalogados como leves.

La ciudad, Chalchuapa, posee un estado de conservación bueno y con potencial valor cultural, especialmente en el centro histórico, pero no posee protección legal en ese sentido. La mayor parte del trazado urbano y de la volumetría de las ciudades es homogéneo. Entre los sistemas constructivos que predominan se encuentra adobe, lámina troquelada y bahareque. Esta ciudad presenta problemas menores por falta de mantenimiento y ha perdido el recubrimiento original en vías de circulación. Se infiere las necesidades orientadoras para las remodelaciones de edificios con valor cultural y protección legal de la ciudad.

Un factor relevante es el deterioro del patrimonio cultural edificado que es paulatinamente sustituido por construcciones de uso comercial con poco o ningún valor patrimonial o arquitectónico, estos inmuebles con valor cultural tiene un potencial económico turístico que podría servir de punto de partida para el desarrollo económico y social del centro histórico de la ciudad de Chalchuapa. 
La falta de estrategias, planes y programas de desarrollo sostenible que interrelacionen la gestión del patrimonio cultural edificado con el crecimiento de las ciudades, es un problema serio en el que se deben tomar las medidas necesarias con el fin de proteger y salvaguardar los patrimonios nacionales.

En Chalchuapa, en el área de estudio determinada para la investigación, se tiene que el estilo predominante en las viviendas del centro histórico es el eclecticismo local, con el $62 \%$, pues, es un estilo propio y auténtico de la ciudad que se presenta a partir de la época de la colonia. El otro estilo que continúa es la arquitectura popular, con un 35\% del total de las viviendas. Dicha arquitectura ha venido creciendo en los últimos años, principalmente las nuevas construcciones se han realizado bajo este estilo, que se caracteriza por no contar con criterios de diseño, alterando la autenticidad de la ciudad porque no se adecuan al entorno. En menor proporción se encuentran el estilo ecléctico, Art Déco. También con un $0.09 \%$ es el estilo colonial, representado por la obra arquitectónica de mayor valor para Chalchuapa, La Iglesia Santiago Apóstol.

Un aspecto muy importante es el estado de conservación de las viviendas. En el área de estudio del Centro Histórico de Chalchuapa, las viviendas se encuentran en un buen estado, es decir, el $97 \%$. El $2 \%$ se encuentran un poco deterioradas, por ejemplo, con grietas en sus paredes. El resto de viviendas son aquellas en las que se encuentran sus paredes y acabados dañados y requieren de una intervención más profunda para la recuperación del inmueble.
En el centro histórico de Chalchuapa, el 56\% pertenece a la subcategoría ambiental, ya que esta arquitectura representa el contexto edificado y la transición entre la arquitectura relevante y vernácula. En algunos casos tiene elementos decorativos más modestos en relación a la arquitectura relevante. El 39\% pertenece a edificaciones que se encuentran no integradas con la tipología existente y sin ningún valor cultural. En cuanto a los monumentos relevantes hay $4 \%$, entre los cuales se encuentran: la Iglesia Santiago Apóstol, las ruinas arqueológicas de Tazumal, el Museo Arqueológico y las ruinas de Casa Blanca.

\section{REFERENCIAS}

Rivera, P. (2010). Marco teórico, elemento fundamental en el proceso de investigación científica. México D. F.: unam.

Sampieri, R., Fernández, C., Baptista, P. (2007). Metodología de la investigación ( $2^{\mathrm{a}} \mathrm{ed}$.). México D.F.: Editorial Mc Graw Hill.

Tamayo, M. (1997). El Proceso de la investigación científica. México D.F: Editorial Limusa.

Drumm, A. (2005). Introducción a la Planificación del Ecoturismo ( $2^{\mathrm{a} e d}$.). Estados Unidos: The Nature Conservancy, Airlington, USA.

Instituto Geográfico Nacional. (1992). Monografías del departamento y Municipios de Santa Ana. El Salvador. 